coloproctology $2016 \cdot 38: 217$

DOI 10.1007/s00053-016-0091-6

Online publiziert: 7. Juli 2016

๑) Springer-Verlag Berlin Heidelberg 2016

CrossMark

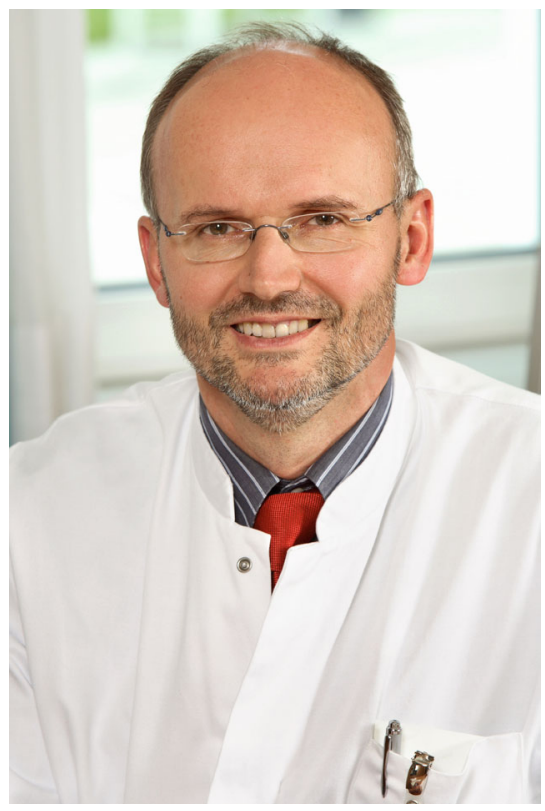

Abb. 1 A Prof. Dr. Alois Fürst, neuer federführender Herausgeber der coloproctology

Sehr geehrte Leserinnen und Leser,

wie sie der Ausgabe Bd. 38, Heft 1 entnehmen konnten, hat sich das Herausgeberboard der Zeitschrift verändert. Der Springer-Verlag und ich haben uns für die gute Zusammenarbeit mit den bisherigen Mitherausgebern bedankt.

Am deutschen Chirurgenkongress in Berlin fand am 28.4.2016 ein Treffen mit den neuen Mitherausgebern statt. Bei

\title{
T. Hager
}

Kronach, Deutschland

\section{Jahre am Steuer der coloproctology}

\section{Prof. Thorolf Hager nimmt Abschied}

diesem Treffen habe ich meinen Rückzug als verantwortlicher Herausgeber mitgeteilt. Nach über 30 Jahren in dieser Funktion bin ich der Meinung, dass ein neues Herausgeberboard auch einen neuen (jüngeren!) verantwortlichen Herausgeber braucht.

In dieser Sitzung wurde, auch nach Rücksprache mit dem Verlag, Prof. Dr. Alois Fürst, Regensburg, zum neuen Herausgeber vorgeschlagen und einstimmig angenommen (• Abb. 1).

Prof. Fürst ist im Bereich Koloproktologie sehr erfahren und viele Jahre tätig. Er leitet die Abteilung Allgemeine und Visceralchirurgie am Caritas-Krankenhaus St. Josef in Regensburg. Prof. Fürst ist in der deutschen Gesellschaft für Chirurgie gut vernetzt, ebenso in der Deutschen Gesellschaft für Koloproktologie.

Ich bin mir sicher, dass er und das neue Herausgebergremium die Zeitschrift coloproctology weiter voranbringen. Geplant ist langfristig die Aufnahme der Zeitschrift in PubMed, was v. a. für Assistenten an Unikliniken für Publikationen in der Zeitschrift von Bedeutung sein kann. Zudem dürfen Sie weitere Schwerpunktthemen erwarten.

Ich möchte mich insbesondere auch bei Christiane Jurek für die jahrelange sehr gute Zusammenarbeit bedanken. Das hat viel Freude gemacht!
Meinem Freund Prof. Fürst wie auch den Mitherausgebern wünsche ich viel Erfolg mit der coloproctology und unseren Lesern weiterhin großes Interesse und viele wichtige Informationen durch die Zeitschrift.

Alles Gute weiterhin und bleiben Sie der Zeitschrift gewogen!

Ihr
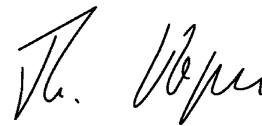

Th. Hager

\section{Korrespondenzadresse}

\section{Prof. T. Hager}

Dobersgrund 87, 96317 Kronach, Deutschland th.hager@web.de

Interessenkonflikt. T. Hager gibt an, dass kein Interessenkonflikt besteht. 